\title{
Serum Cytokine Profiles in Experimental Human Malaria \\ Relationship to Protection and Disease Course after Challenge
}

Rafael Harpaz, * Robert Edelman, * Steven S. Wasserman, * Myron M. Levine, "* Jonathan R. Davis, * and Marcelo B. Sztein * Departments of ${ }^{*}$ Medicine and ${ }^{\ddagger}$ Pediatrics, Center for Vaccine Development, University of Maryland School of Medicine, Baltimore, Maryland 21201

\begin{abstract}
Serum cytokine profiles were evaluated in immunized and nonimmunized human volunteers after challenge with infectious Plasmodium falciparum sporozoites. Three volunteers had been immunized with $x$-irradiated sporozoites and were fully protected from infection. Four nonimmune volunteers all developed symptomatic infection at which time they were treated. Sera from all volunteers were collected at $\sim 20$ time points during the 28-d challenge period; levels of IL-1 $\alpha$, IL-1 $\beta$, IL-2, IFN- $\gamma$, tumor necrosis factor- $\alpha$, IL-4, IL-6, granulocyte macrophage-colony-stimulating factor, and soluble $\mathrm{CD4}, \mathrm{CD8}$, and IL-2 receptor (sCD4, sCD8, and sIL-2R, respectively) were determined by ELISA. C-reactive protein (CRP) was assayed by radial immunodiffusion. Parasitemic subjects developed increases in CRP and IFN- $\gamma$, with less marked increases in SIL2R and sCD8; the other cytokines tested did not change. CRP increases were abrupt and occurred at the onset of fever (day 14 after challenge). IFN- $\gamma$ increases were also abrupt, preceding those of fever and CRP by one day. Increases in SIL-2R and sCD8 were more gradual. Increases in fever, CRP, IFN- $\gamma$, and SCD8 were concordant in each volunteer. Early IL-6 increases were noted in the protected vaccinees. Thus, after challenge with virulent $\boldsymbol{P}$. falciparum, unique systemic cytokine profiles were detectable both in immunized, nonparasitemic volunteers and in unvaccinated, parasitemic subjects. The contrasting cytokine profiles in the two groups may relate to mechanisms of protection and immunopathology in experimental human malaria. ( J. Clin. Invest. 1992. 90:515-523.) Key words: vaccines - interferon- $\gamma$ • interleukin - Plasmodium falciparum • sporozoites
\end{abstract}

\section{Introduction}

Immune responses to invading organisms have long been known to exert beneficial as well as occasionally harmful effects on the host. In malaria, extensive evidence supports a role

This work was presented in part at the 40th Annual Meeting of the American Society of Tropical Medicine and Hygiene, Boston, MA, 1-5 December 1991.

Address correspondence to Dr. M. B. Sztein, Center for Vaccine Development, University of Maryland School of Medicine, 10 South Pine Street, Baltimore, MD 21201.

Received for publication 13 December 1991.

J. Clin. Invest.

(C) The American Society for Clinical Investigation, Inc. 0021-9738/92/08/0515/09 \$2.00

Volume 90 , August 1992, 515-523 for cytokines in both protection from, and immunopathology of, exoerythrocytic (EE) ${ }^{1}$ and blood stage infection.

IFN- $\gamma$ directed at EE stage parasites protects rodents, primates, and in vitro human hepatocytes (1). IL-1, IL-6, and tumor necrosis factor (TNF- $\alpha$ ) may also provide protection against EE stage infection $(2,3)$. IFN- $\gamma(4-6)$ and TNF- $\alpha(5$, 6 ) both appear to protect against blood-stage infections, leading to the development of "crisis forms", or damaged intraerythrocytic parasites circulating in the blood. The protective role for these cytokines has been confirmed with parasitized erythrocytes in vitro as well $(4,7)$, and they appear to have an inhibitory role in gametocyte infectivity, thereby blocking transmission (8). In human malaria, no information is available regarding a protective role for cytokines.

Sterile immunity has been induced in animals after their immunization with attenuated sporozoites. Clyde et al. and Riekmann et al. similarly protected volunteers in a series of studies in the 1970's by using x-irradiated sporozoites (reviewed in 9). These studies served as the rationale for subsequent efforts to develop sporozoite-based subunit vaccines. The first generation of these vaccines, based on the immunodominant repetitive epitope of the major circumsporozoite protein, produced only modest protection despite seemingly good humoral responses (9). In view of the well documented role for cellular immunity and cytokines in antisporozoite protection in rodents and in primates $(1-3,10)$, demonstration of changes in cytokines in protected human volunteers would suggest a similar role in humans.

In terms of immunopathology, cytokines may participate in nonspecific malaria symptomatology (e.g., fever), and in more specific clinical manifestations of malaria such as hemostatic changes, cerebral malaria (11-14), hypergammaglobulinemia, Burkitt's lymphoma (15), and immunosuppression (16-18).

To explore the role of cytokines in the presumed immunopathology of human malaria, investigators have studied serum cytokine levels in a variety of clinical settings in patients with malaria $(14,19-36)$. These studies have been of necessity primarily cross-sectional, done after the onset of symptoms and the initial stages of clinical illness. Such cross-sectional studies have not been designed to recognize preclinical or transient peaks in cytokines, several of which have extremely short serum half-lives $(19,23,24,36-39)$. The sequential, prospective characterization of cytokine levels during infection with malaria could provide additional insight into their pathogenic role in the disease and might ultimately suggest therapeutic interventions.

1. Abbreviations used in this paper: CRP, C-reactive protein; EE, exoerythrocytic; GM-CSF, granulocyte macrophage-colony-stimulating factor; TNF- $\alpha$, tumor necrosis factor $\alpha$. 
We report here our evaluation of cytokine levels in the sera of three immunized and four nonimmunized volunteers before and after they were successfully challenged with infectious Plasmodium falciparum sporozoites. The clinical aspects of this study are described elsewhere (40).

\section{Methods}

Volunteers, immunization, and challenge. Volunteer selection, informed consent, medical screening, immunization, and challenge have all been previously reported $(40,41)$. The protocol was approved by the Human Volunteer Research Committee of the University of Maryland. Briefly, seven healthy adult males with no prior exposure to malaria were selected. Three (identified as Vol. 2, 3, and 7) were immunized with attenuated $P$. falciparum sporozoites delivered by the bites of $\mathrm{x}$-irradiated mosquitoes. $25 \mathrm{~d}$ after the final immunizing dose, they and four nonimmunized volunteers (Vol. 1, 4, 5, and 6) were challenged with the bites of nonirradiated $P$. falciparum-infected mosquitoes. Volunteers were closely monitored for the development of signs, symptoms, and parasitemia, as determined by Giemsa-stained thick smears, and retrospectively confirmed by blood culture. Subjects were permitted acetaminophen for symptoms, and were immediately treated with conventional curative doses of chloroquine upon microscopic detection of parasites. Early morning serum samples were collected from all volunteers at $\sim 20$ time-points, including before challenge, daily for the first $16 \mathrm{~d}$ after challenge, and at several additional times through day 28 after challenge. Samples were stored frozen at $-20^{\circ} \mathrm{C}$ and were not thawed more than three times before assay; cytokine levels in serum spiked with recombinant standards were unaffected by repeated cycles of freeze-thawing (data not shown).

Assays. Serum determinations were conducted using commercial ELISA kits according to the manufacturer's instructions. Sensitivity and performance of the kits were generally close to manufacturer specifications except as noted: double sandwich-type ELISA methods were used to assay IL-4, IL-6, granulocyte macrophage-colony-stimulating factor (GM-CSF) (Genzyme Corp., Boston, MA; sensitivity 90, 150, and $7.5 \mathrm{pg} / \mathrm{ml}$, respectively; pooled normal serum levels reported by manufacturer as undetectable), TNF- $\alpha$, IFN- $\gamma$ (Endogen, Inc., Boston, MA; sensitivity for both $10 \mathrm{pg} / \mathrm{ml}$; detected levels in normal subjects reported by manufacturer as being under 10 and $100 \mathrm{pg} / \mathrm{ml}$, respectively), soluble IL-2 receptor, soluble CD4, and soluble CD8 (sIL2R, sCD4, and sCD8, respectively) ( $\mathrm{T}$ Cell Sciences, Inc., Cambridge, MA; sensitivity 50,12 , and $50 \mathrm{U} / \mathrm{ml}$, respectively; detected levels in normal subjects reported by manufacturer as under 477,62 , and 533 $\mathrm{U} / \mathrm{ml}$, respectively), and IL- $1 \beta$ (Cistron Biotechnology, Pine Brook, $\mathrm{NJ}$; sensitivity in our laboratory $30 \mathrm{pg} / \mathrm{ml}$ ). Competitive ELISA methods were used to assay IL- $1 \alpha$ and IL-2 (Assay Research, Inc., College Park, MD; sensitivity for both $100 \mathrm{pg} / \mathrm{ml}$, detected levels in normal subjects reported by manufacturer as being under 2 and $4 \mathrm{ng} / \mathrm{ml}$, respectively). Samples were run in duplicate, and recombinant standards were included on every plate, from which cytokine concentrations were calculated. Sera from 10 healthy adults were pooled and heat inactivated and were used in kits as blank and/or diluent where indicated by the manufacturer. Sera from immunized and nonimmunized volunteers were generally run concurrently on each plate. Serum C-reactive protein (CRP) levels were determined by radial immunodiffusion (The Binding Site, Ltd., Birmingham, UK; sensitivity $5 \mathrm{mg} /$ liter).

Statistical analysis. Results are expressed as mean values of duplicate determinations; coefficients of variation were generally well under $10 \%$. Undetectable cytokine levels were arbitrarily assigned a value of one half the detection limit for the respective assay. Since published levels for sIL-2R and SCD8 in healthy human controls are variable, but several-fold higher than the limits of detection $(26,28-30,39,42-45)$, results for these factors are displayed as percent change from baseline values prior to challenge.

Data analysis was performed nonparametrically. Repeated measures analysis of variance was performed for each cytokine to evaluate for significance of vaccination status, time, and the interaction between vaccination status and time (i.e., the trajectory of the cytokine levels). Spearman's rank-correlation coefficient was used to assess the significance of relationships among cytokines levels and between cytokines and temperature. Due to the limited number of volunteers in each treatment group, perfect concordance in these relationships yielded a $P$ value no less than 0.08 and is noted in the results as "fully concordant."

\section{Results}

Clinical course of infection. All three vaccinees were protected from infection and remained asymptomatic. The four unvaccinated volunteers developed parasitemia with mild to moderate symptoms, at which time they were treated (40). A summary of the clinical course of infection in the unvaccinated volunteers is shown in Table I. Parasitemia was demonstrated by thick smear beginning on days 11-12.5 and retroactively confirmed by blood culture starting on day 7 for the four nonimmune volunteers. The maximal parasite count was $0.02 \%$ (data not shown). Fever curves are shown in Fig. 1. Three of the four parasitemic volunteers developed fever (to $39.6^{\circ} \mathrm{C}$, $38.3^{\circ} \mathrm{C}$, and $38.0^{\circ} \mathrm{C}$ ); there was no correlation between parasite densities and symptoms or fever (data not shown).

Serum CRP levels after challenge with virulent $P$. falciparum. CRP profiles are shown in Fig. 2. The immunized volunteers had low or undetectable levels of CRP throughout the challenge period. By contrast, the nonimmunized subjects initially had a significantly different pattern $(P=0.0001)$, initially being undetectable and increasing with time $(P=.002)$. The abrupt increases coincided with the onset of fever; furthermore, the magnitude of CRP increase was fully concordant with the degree of fever, with only slightly elevated CRP in the afebrile volunteer (Vol. 1). Of uncertain relevance are small, nonsignificant increases in the levels of CRP (ranging up to 10 $\mathrm{mg} /$ liter) noted on or about four days after challenge in three of four of the nonimmunized subjects (Vol. 1, 4, and 5) and in one of three protected vaccinees (Vol. 7).

Table I. Summary of Clinical Course of Nonimmunized Volunteers after Challenge with P. falciparum*

\begin{tabular}{lcccc}
\hline & $\begin{array}{c}\text { Volunteer } \\
1\end{array}$ & $\begin{array}{c}\text { Volunteer } \\
4\end{array}$ & $\begin{array}{c}\text { Volunteer } \\
5\end{array}$ & $\begin{array}{c}\text { Volunteer } \\
6\end{array}$ \\
\hline $\begin{array}{l}\text { Onset of positive } \\
\text { culture }\end{array}$ & 7 & 7 & 7 & 7 \\
$\begin{array}{l}\text { Onset of patency } \\
\text { Start of }\end{array}$ & 11.5 & 12.5 & 11 & 12 \\
$\begin{array}{l}\text { chloroquine } \\
\text { therapy }\end{array}$ & 11.5 & 13 & 11.5 & 12.5 \\
$\begin{array}{l}\text { Onset of } \\
\text { symptoms }\end{array}$ & 7 & 14 & 7 & 13 \\
$\begin{array}{l}\text { Onset of fever } \\
\text { (n) }\end{array}$ & - & 14 & 14 & 14 \\
\hline
\end{tabular}

* Onsets are shown in days after challenge by the bites of infected mosquitos in the four healthy volunteers. Immunized volunteers remained afebrile, asymptomatic, and free of parasitemia until $28 \mathrm{~d}$ after challenge at which time they received chloroquine.

${ }^{\ddagger}$ Patency is defined as the time at which $P$. falciparum parasites were first visualized in the circulating red blood cells of volunteers in thick blood smears.

${ }^{8}$ Symptoms included: malaise, chills, myalgia, headache, sweats, diarrhea, nausea, vomiting, dizziness, lower back pain, and cough. 

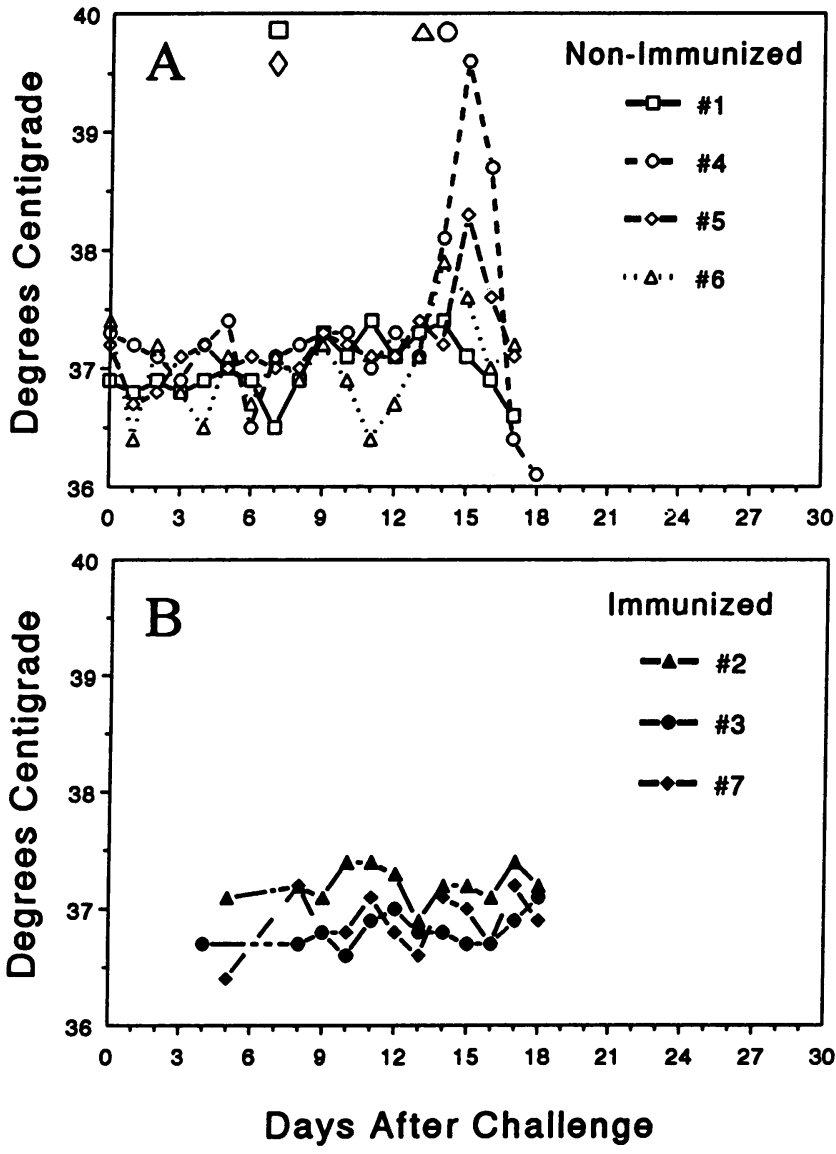

Figure 1. Fever curves after challenge with virulent $P$. falciparum. Volunteers were immediately treated upon microscopic demonstration of parasitemia in thick blood smears. Symbols at top of figure indicate onset of symptoms (see Table I) in corresponding volunteers.

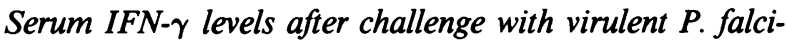
parum. IFN- $\gamma$ patterns in the two treatment groups were significantly different $(P=0.0002)$. As shown in Fig. 3, IFN- $\gamma$ levels in the immunized volunteers were undetectable throughout the challenge period. Levels in the nonimmunized subjects were initially undetectable but increased abruptly with time $(P$ $=0.0001$ ). These increases were also fully concordant with the magnitude of fever and of CRP, but they preceded them by $\sim 1 \mathrm{~d}$.

Serum SCD8 and sIL-2R levels after challenge with virulent $P$. falciparum. Patterns of SCD8 in parasitemic and nonparasitemic subjects are shown in Fig. 4. Levels were somewhat erratic in the immunized volunteers but did not change signifcantly with time. The pattern in parasitemic subjects was significantly different $(P=0.008)$, though the increases occurring after infection did not reach significance $(P=0.08)$. Those increases were gradual, and in one subject (Vol. 4), levels transiently increased during the first week after challenge and then increased even more markedly. SCD8 peaks coincided with, and their magnitude was fully concordant with, those of fever, CRP, and IFN- $\gamma$ among the different volunteers.

Fig. 5 shows the kinetics of sIL-2R in the two groups of volunteers. In two of three immunized subjects (Vol. 2 and 3), levels remained within published range for normals $(26,28-$ $30,39,42-45$ ); the third subject (Vol. 7) had modestly in- creased sIL-2R even before challenge but with no clear trend through the challenge period. In the nonimmune, parasitemic volunteers, sIL-2R levels tended to increase; however, neither those increases nor the differences in SIL-2R profiles between the two volunteer groups were significant $(P=0.09$ and $P$ $=0.12$, respectively). Increases in sIL-2R also were gradual and maximal levels coincided in time with the development of fever, increased CRP, and IFN- $\gamma$. Serum was not available for sIL-2R determination from nonimmunized volunteer 6 during the fourth week of the trial; concentration in a plasma sample collected $42 \mathrm{~d}$ after challenge had fallen to baseline ( $555 \mathrm{U} / \mathrm{ml}$ ).

Serum $T N F-\alpha$ levels after challenge with virulent $P$. falciparum. Nonparasitemic volunteers had stable levels of TNF- $\alpha$ throughout the challenge (Fig. 6), though for one of the three (Vol. 3), the levels were moderately and persistently high. In two of the four parasitemic volunteers (Vol. 1 and 6), TNF- $\alpha$ levels appeared to increase without a defined pattern from their respective baselines, though as a group, neither these changes nor the differences with the immunized volunteers were statistically significant $(P=0.15$ and $P=0.71$, respectively $)$. There were no clinically distinctive features in these two individuals, who were the less febrile of the parasitemic subjects.
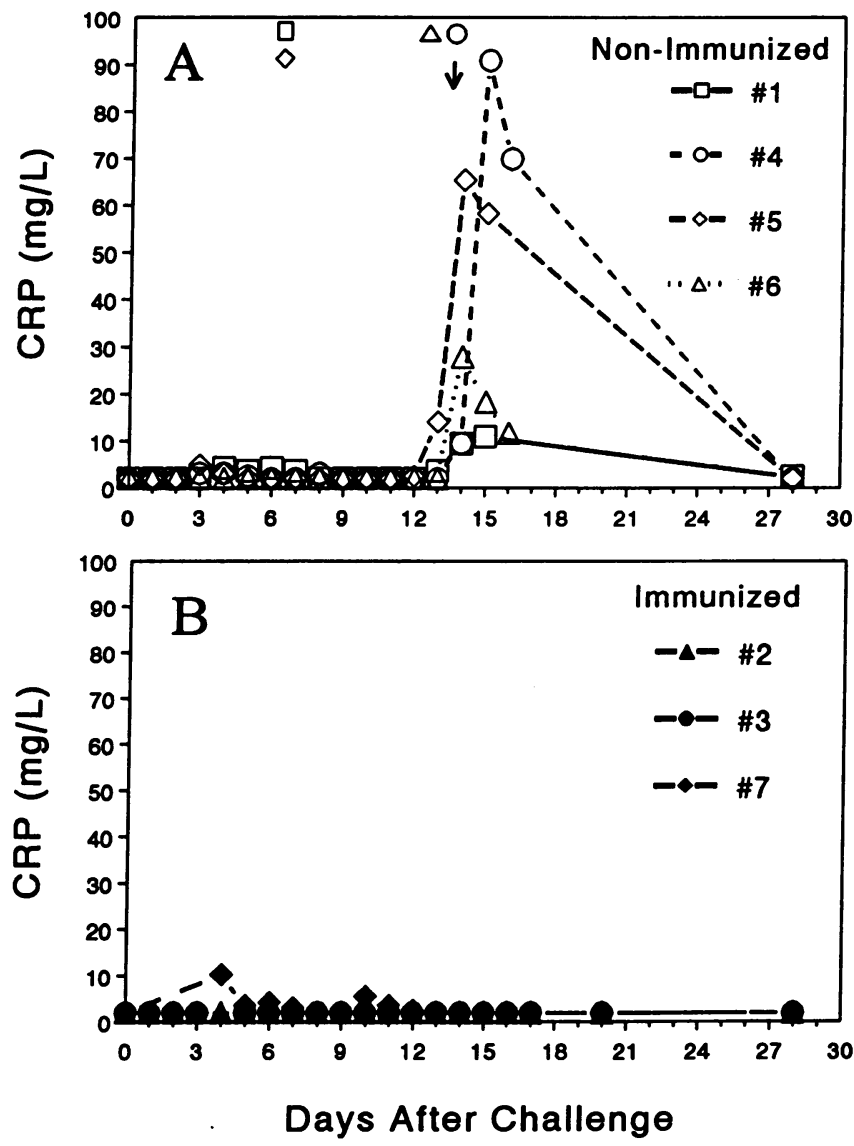

Figure 2. Serum CRP levels after challenge with virulent $P$. falciparum. Levels were determined by radial immunodiffusion (sensitivity $5 \mathrm{mg} /$ liter). Increases in the nonimmunized volunteers were significant $(P=0.002)$, as were differences between the two volunteer groups $(P=0.0001)$. Symbols at top of figure as in legend to Fig. 1; arrow indicates onset of fever in febrile volunteers. 

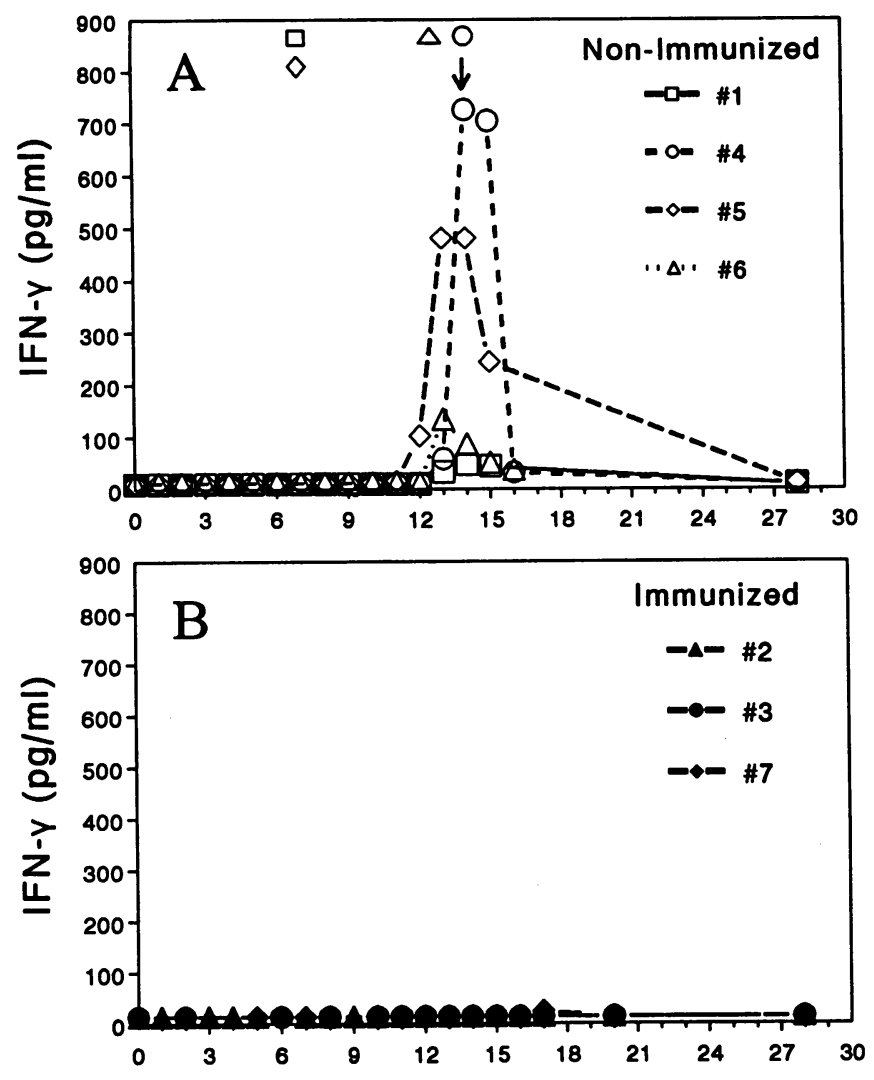

Days After Challenge

Figure 3. Serum IFN- $\gamma$ levels after challenge with virulent $P$. falciparum. Levels were determined by double sandwich-type ELISA (sensitivity $10 \mathrm{pg} / \mathrm{ml}$ ). Increases in the nonimmunized volunteers were significant $(P=0.0001)$, as were differences between the two volunteer groups $(P=0.0002)$. Symbols and arrow at top of figure as in legend to Fig. 2 .

Serum IL-6 levels after challenge with virulent $P$. falciparum. For IL-6 (Fig. 7), profiles of the two volunteer groups differed $(P=0.02)$. In the case of this cytokine, however, nonimmunized, parasitemic volunteers had undetectable levels throughout the challenge period, whereas two of three vaccinees (Vol. 2 and 3) had variable, abrupt increases within $2 \mathrm{~d}$ after challenge that, as a group, did not reach statistical significance $(P=0.06)$.

Levels of remaining cytokines after challenge with virulent $P$. falciparum. Significant temporal changes or differences between treatment groups were not noted for IL- $\alpha$, IL-1 $\beta$, IL-2, IL-4, GM-CSF, and SCD4 (data not shown). Of note, however, were increases in IL-4 recorded in only one of three protected vaccinees (Vol. 2) that occurred within $2 \mathrm{~d}$ after challenge and that showed a marked covariance with the IL-6 levels in that volunteer (Fig. 8).

\section{Discussion}

The importance of cytokines in the protective and pathologic responses to malaria is reflected in a rapidly growing literature on cytokine levels in malaria patients in a variety of settings $(14,19-36)$. To our knowledge, the current investigation is the first prospective analysis of serum cytokine networks in vivo in humans during the evolution of an infectious process such as malaria. This paper is also the first one to compare cytokines in immune and nonimmune individuals during the evolution of the protective response.

In the current clinical trial, vaccinees were fully protected from sporozoite challenge, confirming earlier results (reviewed in 9). The irradiated-sporozoite model continues to be the only way by which sterile antisporozoite immunity has been consistently achievable in humans (9). All nonimmunized subjects developed symptomatic parasitemia. Parasite density was quite low and was not correlated with the degree of fever or symptoms. Ethical considerations dictated prompt treatment of the parasitemic volunteers early in their illness. The studies reported here therefore differ from those done previously in field settings in which cytokine levels were evaluated in patients primarily after they had become ill $(14,19-36)$.

As an acute phase reactant, CRP levels have long been known to correlate well clinically with a variety of nonspecific inflammatory and infectious states, often rising within hours of a stimulus (46-48). Increased levels of CRP have previously
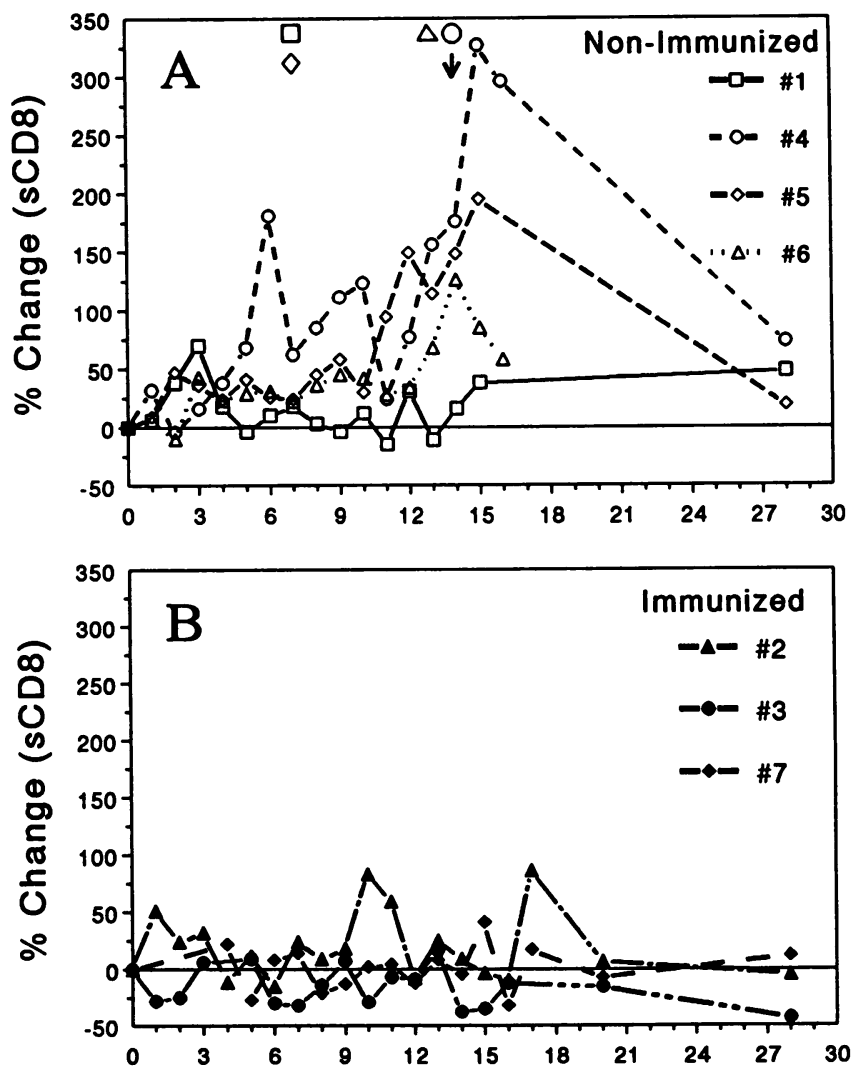

\section{Days After Challenge}

Figure 4. Serum sCD8 levels after challenge with virulent $P$. falciparum. Levels were determined by double sandwich-type ELISA (sensitivity $50 \mathrm{U} / \mathrm{ml}$ ). Results are displayed as percent change from baseline values before challenge (absolute values in $\mathrm{U} / \mathrm{ml}$ before challenge: $201,370,355,280,168,261$, and 545 in Vol. 1-7, respectively). Differences between the two volunteer groups were significant $(P=0.008)$; increases in the nonimmunized volunteers approached significance $(P=0.08)$. Symbols and arrow at top of figure as in legend to Fig. 2. 

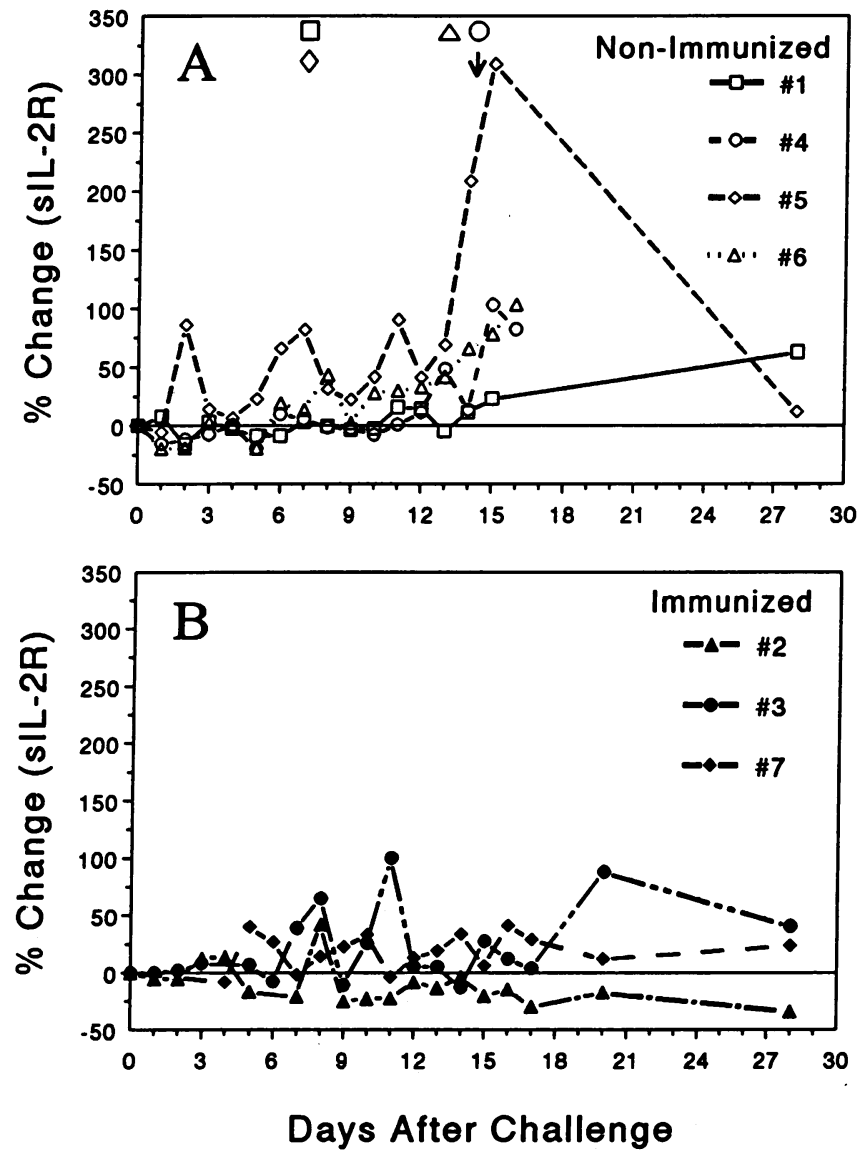

Figure 5. Serum sIL-2R levels after challenge with virulent $P$. falciparum. Levels were determined by double sandwich-type ELISA (sensitivity $50 \mathrm{U} / \mathrm{ml}$ ). Results are displayed as percent change from baseline values before challenge (absolute values in $\mathrm{U} / \mathrm{ml}$ before challenge: $456,460,352,513,262,527$, and 688 in Vol. 1-7, respectively). There were no significant temporal changes in the parasitemic volunteer group $(P=0.09)$ nor significant differences between groups $(P=0.12)$. Symbols and arrow at top of figure as in legend to Fig. 2.

been associated with malaria in Zambian children and adults (49). Our study demonstrated 6- to 45-fold increases in CRP levels in the parasitemic subjects. Increases were quite abrupt, coincident, and concordant in magnitude with fever but after the onset of parasitemia (as determined by positive thick smears) by 2-3 d. Furthermore, using the more sensitive culture method to determine parasitemia, the onset of parasitemia was found to precede CRP rises by $\sim 7 \mathrm{~d}$. The reason for the delayed increase in CRP in this study is unclear, though the temporal relationship and the concordance of peak CRP and IFN- $\gamma$ concentrations among the different volunteers suggests that rises in both factors might be related. In fact, along with IL-1 and IL-6, IFN- $\gamma$ has been shown to enhance production of acute phase proteins $(48,50)$. Increased CRP levels have been noted in vivo after the combined administration of recombinant IFN- $\gamma$ and TNF- $\alpha$ in a phase I trial (51). Increased CRP may serve as more than a simple marker for acute phase response in malaria. Nonspecific effector functions have long been directly or indirectly attributed to CRP (48); CRP appears, in addition, to play a specific protective role in malaria by blocking both establishment and development of the EE stage $(52,53)$.

Our four unvaccinated volunteers had highly significant increases in serum IFN- $\gamma$ early in parasitemia. The relevance of these findings is strengthened by several observations pointing to a protective role of IFN- $\gamma$ against blood-stage infection both in vitro $(4,7)$ and in vivo $(4,6)$. Conflicting results have been presented regarding serum IFN- $\gamma$ concentrations in patients with various infectious processes $(38,54)$ including malaria, with several investigators reporting undetectable IFN- $\gamma$ levels in malaria patients $(23,26,31)$.

While these discrepancies may be due to differences in assays, patient populations, or Plasmodial strains, our results suggest that peak IFN- $\gamma$ levels, though potentially quite high, are very transient and can easily be missed in a clinical setting. Three of our four unprotected subjects developed abrupt IFN$\gamma$ increases, rising as much as 100 -fold in $<48 \mathrm{~h}$ and returning to baseline levels equally rapidly. While rapid changes in cytokine levels may be caused by chloroquine treatment or by the immunosuppressive effects of chloroquine $(55,56)$, the timing of treatment (Table I) with respect to IFN- $\gamma$ peaks makes this explanation unlikely. Others have noted a complete normalization of IFN- $\gamma$ levels in patients with malaria within just $24 \mathrm{~h}$
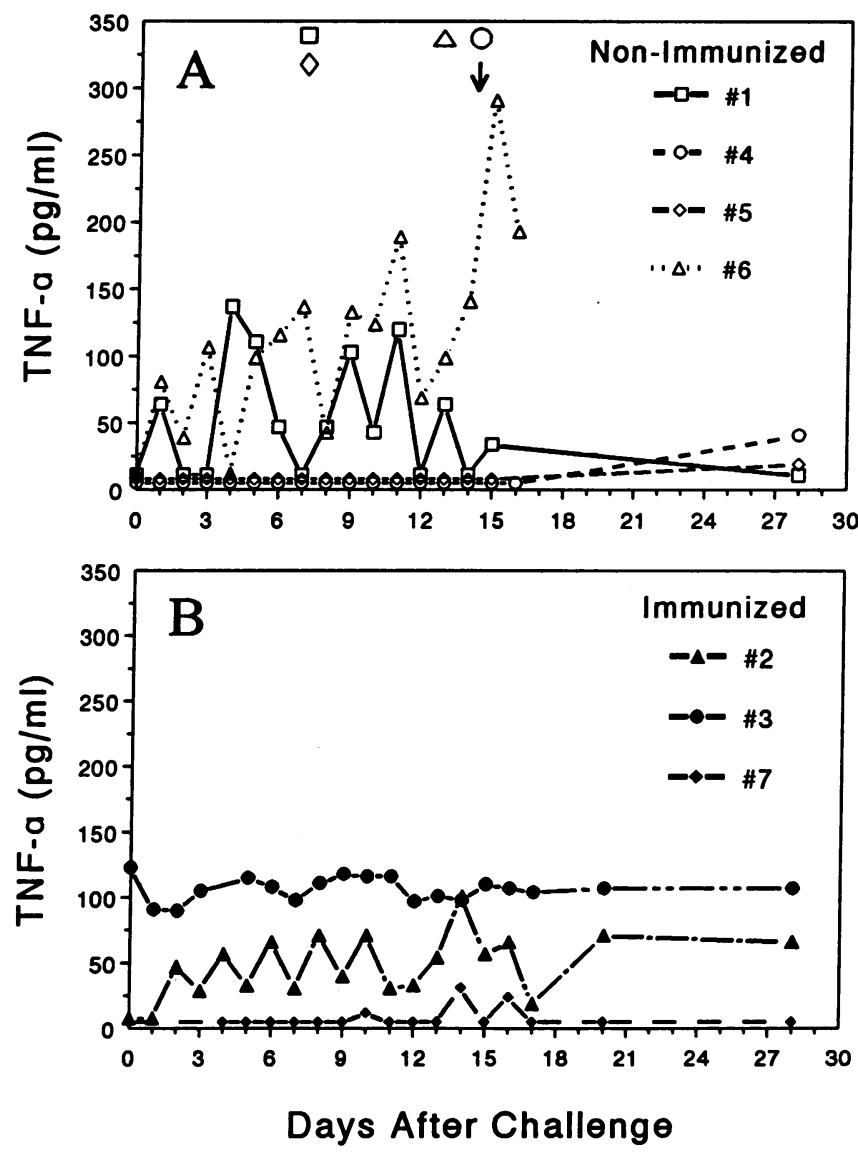

Figure 6. Serum TNF- $\alpha$ levels after challenge with virulent $P$. falciparum. Levels were determined by double sandwich-type ELISA (sensitivity $10 \mathrm{pg} / \mathrm{ml}$ ). There were no significant temporal changes within volunteer groups $(P=0.71)$ nor significant differences between groups $(P=0.15)$. Symbols and arrow at top of figure as in legend to Fig. 2. 

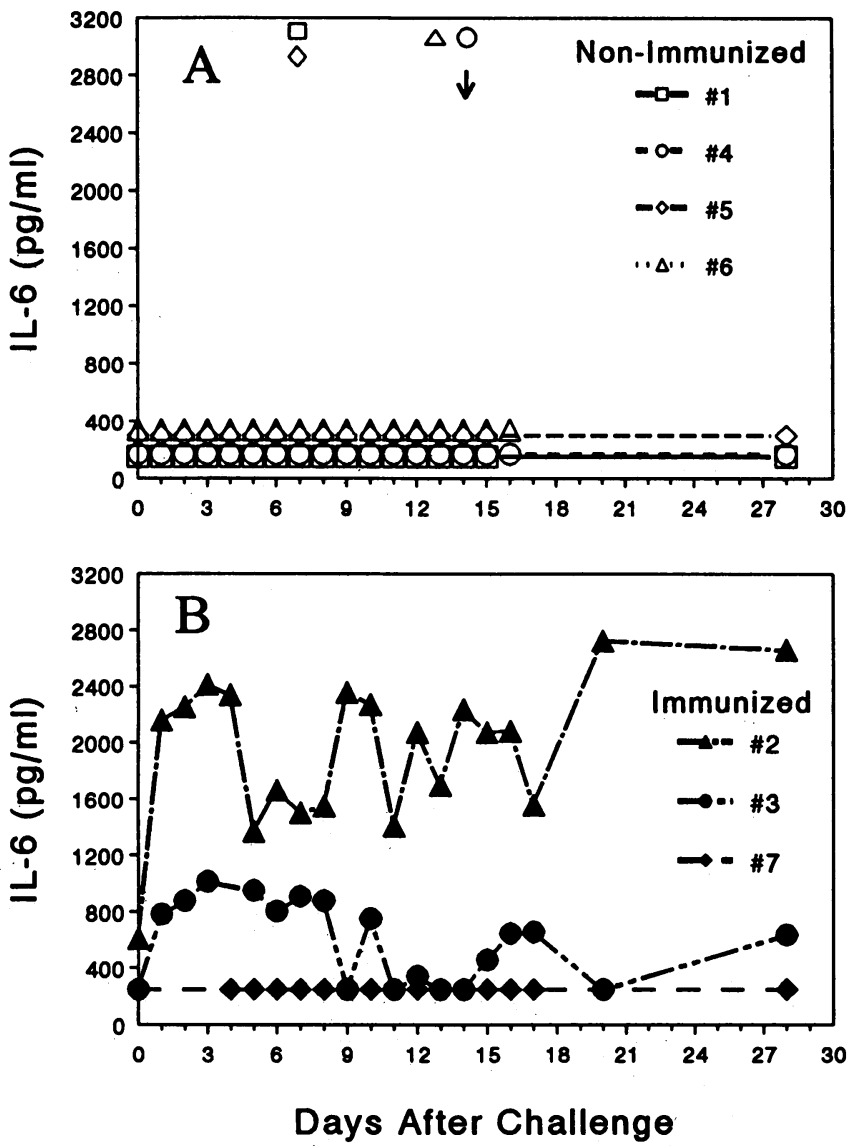

Figure 7. Serum IL-6 levels after challenge with virulent $P$. falciparum. Levels were determined by double sandwich-type ELISA (sensitivity $150 \mathrm{pg} / \mathrm{ml}$ ). Profiles of the two volunteer groups were statistically different $(P=0.02)$. IL-6 increases in vaccinees did not reach statistical significance $(P=0.06)$. Symbols and arrow at top of figure as in legend to Fig. 2.

$(19,36)$. Furthermore, IFN- $\gamma$ levels determined serially in serum of infected mice or in supernatants from their splenocytes had kinetics remarkably similar to those in the human volunteers $(4,6,57,58)$. In these studies, peak IFN- $\gamma$ concentrations developed during early parasitemia and declined rapidly before the time of peak parasite density. As in the volunteers, the triggers for the abrupt changes in murine IFN- $\gamma$ levels remain speculative, but sudden increases in IFN- $\gamma$ levels have been demonstrated in mice in vivo (57) and in vitro (59) after schizont release from erythrocytes, suggesting that schizogony may be responsible for the observed surge of IFN- $\gamma$ in the volunteers.

In murine models, IFN- $\gamma$ appears to be a crucial mediator of cerebral malaria, acting perhaps by boosting the release and the biological effects of TNF- $\alpha(11,13,60)$. Most investigators have found no correlation of serum IFN- $\gamma$ levels with parasite density, disease severity, or the occurrence of cerebral involvement in patients with malaria $(21,24,34-36)$. In the present study, IFN- $\gamma$ levels had normalized in the parasitemic volunteers before parasite density could increase or serious complications could develop, and a triggering role for IFN- $\gamma$ in severe malaria could conceivably be missed in clinical studies due to its transient and early nature. In our volunteers, peak IFN- $\gamma$ concentrations correlated with the degree of fever, preceding it by one day. IFN- $\gamma$ is an endogenous pyrogen (37); its role as a chief mediator of fever in the parasitemic volunteers is supported by the concurrent undetectable or uncorrelated levels of other recognized endogenous pyrogens (e.g. IL-1, IL-6, TNF- $\alpha$ ).

Neopterin is a guanosine metabolite of IFN- $\gamma$-activated macrophages. It is being evaluated in urine from patients with malaria as a surrogate marker for serum IFN- $\gamma$, with conflicting results (19-21). In a separate component of this investigation, serial urine neopterin levels were measured in the seven volunteers (61). Abrupt increases were noted in urine neopterin that followed by one day the increased serum IFN- $\gamma$ levels that we now report. The two volunteers with the highest serum IFN- $\gamma$ (Vol. 4 and 5) also had the highest levels of urine neopterin, while volunteers 1 and 7 both had increased neopterin levels despite minimal serum IFN- $\gamma$. The similar findings obtained in this well controlled clinical setting between serum IFN- $\gamma$ and urinary neopterin support a role for this compound as a surrogate marker for serum IFN- $\gamma$.

The membrane-associated receptor for IL-2 plays a major regulatory role in the immune response. Additionally, its 55$\mathrm{kD}$ subunit is released in vitro and in vivo after various stimuli in IL-2-binding forms (sIL-2R) (62). While a physiologic function for sIL-2R remains a subject of debate, it is present in normal adult serum, and its levels are elevated during childhood (42), old age (43), and in an array of disease states characterized by increased $T$ cell activation $(30,42,44,45)$. Our results show that the unvaccinated volunteers developed gradual increases in sIL-2R that approached, but did not reach, statistical significance. Levels peaked at the onset of fever and appeared to decline with time. IL-2 levels, on the other hand, showed neither differences between treatment groups nor any temporal trends (data not shown). Others have made similar observations in a variety of settings and populations $(17,27-$ 30 ). Results from those studies repeatedly showed increases in sIL-2R in patients with malaria. Correlations of sIL-2R with parasite density or with symptoms have been inconsistent, though concentrations appeared higher in those with cerebral malaria $(28,29)$. The lack of correlation of sIL-2R with the

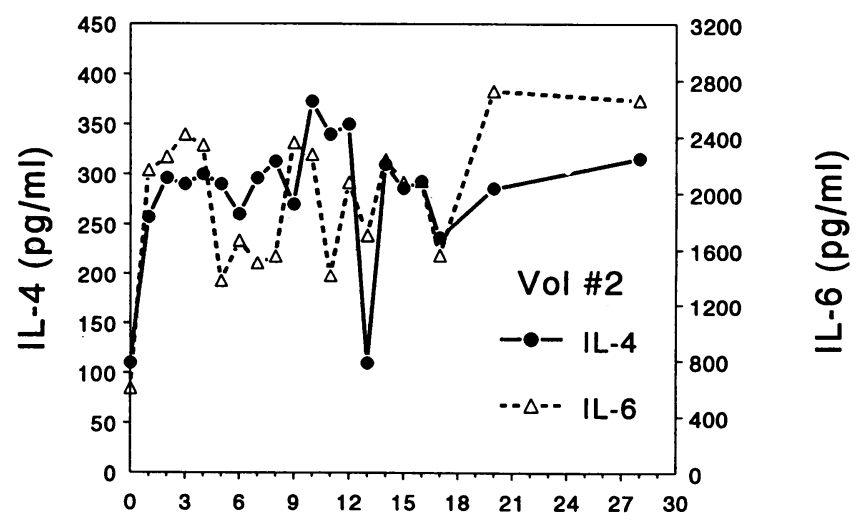

Days After Challenge

Figure 8. Serum IL-4 and IL-6 levels in vaccinated Vol. 2 after challenge with virulent $P$. falciparum. Levels were determined by double sandwich-type ELISA (sensitivity, $90 \mathrm{pg} / \mathrm{ml}$ and $150 \mathrm{pg} / \mathrm{ml}$ for IL-4 and IL-6, respectively). 
degree of fever observed by others has been confirmed by our observations (29).

Levels of sIL-2R may serve as a marker for $T$ cell activation in vivo (62). Additionally, elevation of sIL-2R levels have been postulated to play a causal role in immunosuppression, a well described phenomenon in malaria (17) and certain other disease states (44). High levels of sIL-2R might bind IL-2, reducing the local concentration of IL-2 available and thereby leading to a downregulation of the immune response $(17,44,62)$. Such a process may contribute to the suboptimal natural immunity that develops to sporozoites and to blood-stage malaria in endemic regions. We observed no inverse reduction in serial IL-2 levels as sIL-2R concentrations increased, though the number of volunteers was too small to exclude such reductions with any certainty.

The CD8 glycoprotein is expressed on the surface of MHC class I-restricted cytotoxic and suppressor T cells. Supernatants of $\mathrm{CD}^{+}{ }^{+}$human cell lines contain high levels of soluble, shortened CD8 (sCD8) (39). The release of sCD8 is increased upon stimulation in vitro (39) and it is present in high concentrations in sera from patients with various malignant, autoimmune, and infectious processes $(39,45,63)$. The results presented here show a gradual increase in SCD8 concentrations in nonprotected volunteers, reaching peak concentrations at the time of the development of fever and with concordant magnitude. Levels normalized within two weeks after parasitemia. Similar changes in SCD8 levels have been reported recently in patients with malaria (26). Increased sCD8 levels may be related to malaria-associated immunosuppression, serving as a marker for $\mathrm{CD}^{+} \mathrm{T}$ cell activation (39), although conflicting results have been reported regarding reversal of malaria immunosuppression after depletion of $\mathrm{CD}^{+} \mathrm{T}$ cells $(16,18)$. Alternatively, serum SCD8 may be directly immunosuppressive by binding MHC I antigen and thereby interfering with cell-to-cell communication (64).

We observed TNF- $\alpha$ increases in two of the four parasitemic subjects; these individuals had no distinctive clinical features. The TNF- $\alpha$ increases occurred before the onset of parasitemia and they lacked a defined pattern. There was also an unexplained, but persistent, moderately elevated level of TNF$\alpha$ in one of the three vaccinees that was present even before challenge. Increased levels of TNF- $\alpha$ have been previously observed in healthy persons (65). The crucial role that TNF- $\alpha$ plays in mediating cerebral malaria, and perhaps other lifethreatening complications of malaria (reviewed in 11,12) was established in animal models and has been supported by determinations of this cytokine in afflicted patients $(14,20-25,31-$ $34)$. Most $(14,21-25,31)$, but not all $(20,32,33)$, studies describe correlations of TNF- $\alpha$ concentrations with fever, parasite density, and indices of disease severity, with increases in a range of several hundred $\mathrm{pg} / \mathrm{ml}$ in a variable majority of patients experiencing uncomplicated disease. Our results in volunteers with very early disease are not inconsistent with these cross-sectional studies. Of note, several observers have noted rapid declines in those malaria patients with elevated TNF- $\alpha$ $(23,32)$, mimicking the rapid declines in TNF- $\alpha$ that have been reported during sepsis (38). TNF- $\alpha$, like IFN- $\gamma$, has a serum half-life measured in minutes to hours $(37,38)$, and its release in vitro and in vivo may be related to schizogony (32, 34 ). While it is unlikely that we missed TNF- $\alpha$ peaks before the initiation of treatment, it may be possible that more marked and consistent increases would have occurred after IFN- $\gamma$ peaks. In vitro splenocyte release of TNF- $\alpha$ appears to follow that of IFN- $\gamma$ in experimental murine malaria (6). Furthermore, transient, dose-dependent spikes of TNF- $\alpha$ follow the administration of rIFN- $\gamma$ during human phase I trials (37). Finally, TNF- $\alpha$ increases in experimental murine malaria are prevented by the monoclonal antibody depletion of IFN- $\gamma$ (13). The biological activity of TNF- $\alpha$ is known to be increased by IFN- $\gamma(60)$, but the effects of increased levels of the two cytokines in human malaria remain unknown.

We found no statistical trends in the parasitemic volunteers for any of the other cytokines evaluated. Some of these cytokines, e.g., GM-CSF, IL-1, and IL-6 have been implicated in experimental animal models of complicated malaria, though the data are not as clear as for TNF- $\alpha$ and IFN- $\gamma$ (reviewed in 11 ). To our knowledge, GM-CSF has never been measured in patients with malaria. IL-1 and IL-6 levels are increased in severe malaria $(21,23,24,31)$ and in septic shock $(38,65)$, with minimal or no increases in uncomplicated disease. IL-1 and IL-6 levels in our subjects with early disease are consistent with these findings. Of course, undetectable serum levels of these and the other cytokines may reflect their local distribution, phasic release, lack of adequate ELISA sensitivity, or presence of serum inhibitory factors (65).

In contrast to parasitemic volunteers, in protected vaccinees only IL-6 had increases approaching statistical significance. Among its potentially protective activities in malaria, IL-6 participates in the establishment of humoral immunity as well as in the acute phase response (50); in that respect, the lack of CRP in the subjects with increased IL-6 is of note. There is also a suggestion of specific anti-EE stage activity by IL-6 at the hepatocyte level (3). Increases in IL-6 in vaccinees, if confirmed, could therefore have a protective function.

Functional subsets of $\mathrm{CD}^{+}$cells called $\mathrm{T}_{h} 1$ and $\mathrm{T}_{h} 2$ cells have been described in mice based on patterns of cytokine secretion; their presence has now been confirmed in humans (66, 67). $T_{h} 2$ cells secrete IL-4, IL-5, IL-6, and IL-10 at the exclusion of IL- 2 and IFN- $\gamma$. The covariation of IL- 4 and IL- 6 noted here in a single vaccinee might be related to this phenomenon.

The mechanisms for antisporozoite protection in immunized human volunteers remain speculative. Our volunteers had increased levels of antisporozoite antibodies (40), and perhaps humoral clearance of the sporozoites prevented establishment of the hepatic stage and immune recognition of the infection. Humoral antisporozoite protection has been demonstrated in mice after passive transfer of immune serum or antisporozoite monoclonal antibody (9); protection of Gambian infants through congenital transfer of antibodies has been suggested as well (9).

While the lack of clear-cut trends in cytokines, in particular IFN- $\gamma$, among the vaccinees may reflect the lack of establishment of EE stage infection; alternatively, and more probably, IFN- $\gamma$ in conjunction with other cytokines is exerting its influence at the local level in the liver and is not readily measurable systemically with available methods and with limited numbers of volunteers.

In summary, we report systemic increases in IFN- $\gamma, \mathrm{CRP}$, sIL-2R, and sCD8 in unprotected volunteers with malaria; the kinetics and relative magnitudes of these increases may have important bearing on the pathogenesis of the disease. We find early increases in systemic IL-6 but unchanging levels of other cytokines in immunized subjects after challenge that may relate to mechanisms of protection against infection. We are 
currently investigating whether these changes were accompanied by alterations in the composition of lymphocyte subpopulations. The ability of lymphocytes obtained from these volunteers to respond to malarial antigens in vitro is also being studied in an effort to provide a comprehensive evaluation of the immunological events taking place during clinical malaria and resistance to malaria infection.

\section{Acknowledgments}

The authors thank Drs. D. F. Clyde and D. A. Herrington for careful review of the manuscript.

This work was supported in part by National Institutes of Health (NIH) contract NO1-Al62553. R. Harpaz is supported by NIH Training Grant T33-A107376.

\section{References}

1. Ferreira, A., L. Schofield, V. Enea, H. Schellekens, P. van der Meide, W. E. Collins, R. S. Nussenzweig, and V. Nussenzweig. 1986. Inhibition of development of exoerythrocytic forms of malaria parasites by $\gamma$-interferon. Science (Wash. DC). 232:881-884.

2. Mellouk, S., R. K. Maheshwari, A. Rhodes-Feuillette, R. L. Beaudoin, N. Berbiguier, H. Matile, F. Miltgen, I. Landau, S. Pied, J. P. Chigot, et al. 1987. Inhibitory activity of interferons and interleukin 1 on the development of Plas modium falciparum in human hepatocyte cultures. J. Immunol. 139:4192-4195.

3. Nussler, A., J. C. Drapier, L. Renia, S. Pied, F. Miltgen, M. Gentilini, and D. Mazier. 1991. L-arginine-dependent destruction of intrahepatic malaria parasites in response to tumor necrosis factor and/or interleukin-6 stimulation. Eur. J. Immunol. 21:227-230.

4. Shear, H. L., R. Srinivasan, T. Nolan, and C. Ng. 1989. Role of IFN- $\gamma$ in lethal and non-lethal malaria in susceptible and resistant murine hosts. J. Immunol. 143:2038-2044.

5. Clark, I. A., N. H. Hunt, G. A. Butcher, and W. B. Cowden. 1987. Inhibition of murine malaria (Plasmodium chabaudi) in vivo by recombinant interferon or tumor necrosis factor, and its enhancement by butylated hydroxyanisole. J. Immunol. 139:3493-3496.

6. Stevenson, M. M., M. F. Tam, and M. Nowotarski. 1990. Role of interferon- $\gamma$ and tumor necrosis factor in host resistance to Plasmodium chabaudi AS. Immunol. Lett. 25:115-122.

7. Kumaratilake, L. M., A. Ferrante, and C. Rzepczyk. 1991. The role of T lymphocytes in immunity to Plasmodium falciparum. Enhancement of neutrophil-mediated parasite killing by lymphotoxin and IFN- $\gamma$ : comparisons with tumor necrosis factor effects. J. Immunol. 146:762-767.

8. Naotunne, T. De S., N. D. Karunaweera, G. Del Giudice, M. U. Kularatne, G. E. Grau, R. Carter, and K. N. Mendis. 1991. Cytokines kill malaria parasites during infection crisis: extracellular complementary factors are essential. $J$. Exp. Med. 173:523-529.

9. Nussenzweig, V., and R. S. Nussenzweig. 1989. Rationale for the development of an engineered sporozoite malaria vaccine. Adv. Immunol. 45:283-334.

10. Weidanz, W. P., and C. A. Long. 1988. The role of T cells in immunity to malaria. Prog. Allergy. 41:215-252.

11. Grau, G. E., P. F. Piguet, P. Vassalli, and P. H. Lambert. 1989. Tumor-necrosis factor and other cytokines in cerebral malaria: experimental and clinical data. Immunol. Rev. 112:49-70.

12. Clark, I. A., and G. Chaudhri. 1989. Relationship between inflammation and immunopathology of malaria. In Malaria: Host Responses to Infection. M. M. Stevenson, editor. CRC Press, Boca Raton, FL. 127-146.

13. Grau, G. E., H. Heremans, P. F. Piguet, P. Pointaire, B. Allet, P. H Lambert, A. Billiau, and P. Vassalli. 1989. Monoclonal antibody against interferon can prevent experimental cerebral malaria and its associated overproduction of tumor necrosis factor. Proc. Natl. Acad. Sci. USA 86:5572-5574.

14. Hemmer, C. J., P. Kern, F. G. E. Holst, K. P. Radtke, R. Egbring, A. Bierhaus, P. P. Nawroth, and M. Dietrich. 1991. Activation of the host response in human Plasmodium falciparum malaria: relation of parasitemia to tumor necrosis factor/cachectin, thrombin-antithrombin III, and protein Clevels. $\mathrm{Am}$. J. Med. 91:37-44.

15. Grau, G. E., K. Frei, P. F. Piguet, A. Fontana, H. Heremans, A. Billiau, P Vassalli, and H. Lambert. 1990. Interleukin-6 production in experimental cerebral malaria: modulation by anti-cytokine antibodies and possible role in hypergammaglobulinemia. J. Exp. Med. 172:1505-1508.

16. Ho, M., H. K. Webster, S. Looareesuwan, W. Supanaranond, R. E. Phillips, P. Chanthavanich, and D. A. Warrell. 1986. Antigen-specific immunosuppression in human malaria due to Plasmodium falciparum. J. Infect. Dis. 153:763-771.

17. Ho, M., H. K. Webster, B. Green, S. Looareesuwan, S. Kongchareon, and
N. White. 1988. Defective production of and response to IL-2 in acute falciparum malaria. J. Immunol. 141:2755-2759.

18. Riley, E. M., O. Jobe, and H. C. Whittle. 1989. CD8 ${ }^{+}$T cells inhibit Plasmodium falciparum-induced lymphoproliferation and gamma interferon production in cell preparations from some malaria-immune individuals. Infect. Im mun. 57:1281-1284.

19. Brown, A. E., H. K. Webster, P. Teja-Isavadharm, and D. Keeratithakul. 1990. Macrophage activation in falciparum malaria as measured by neopterin and interferon-gamma. Clin. Exp. Immunol. 82:97-101.

20. Kremsner, P. G., H. Feldmeier, G. M. Zotter, R. Jansen-Rosseck, W. Graninger, R. M. Rocha, and U. Bienzle. 1989. Immunological alterations in uncomplicated Plasmodium falciparum malaria. Relationship between parasitemia and indicators of macrophage activation. Acta Trop. 46:351-359.

21. Kern, P., C. J. Hemmer, J. Van Damme, H. J. Gruss, and M. Dietrich. 1989. Elevated tumor necrosis factor-alpha and interleukin-6 serum levels as markers for complicated Plasmodium falciparum malaria. Am. J. Med. 87:139143.

22. Grau, G. E., T. E. Taylor, M. E. Molyneux, J. J. Wirima, P. Vassalli, M. Hommel, and P. H. Lambert. 1989. Tumor necrosis factor and disease severity in children with falciparum malaria. $N$. Engl. J. Med. 320:1586-1591.

23. Molyneux, M. E., T. E. Taylor, J. J. Wirima, and G. E. Grau. 1991. Tumour necrosis factor, interleukin-6, and malaria. Lancet. 337:1098. (Letter.)

24. Kwiatkowski, D., A. V. S. Hill, I. Sambou, P. Twumasi, J. Castracane, K. R. Manogue, A. Cerami, D. R. Brewster, and B. M. Greenwood. 1990. TNF concentration in fatal cerebral, non-fatal cerebral, and uncomplicated Plasmodium falciparum malaria. Lancet. 336:1201-1204.

25. Shaffer, N., G. E. Grau, K. Hedberg, F. Davachi, B. Lyamba, A. W. Hightower, J. G. Breman, and P. Nguyen-Dinh. 1991. Tumor necrosis factor and severe malaria. J. Infect. Dis. 163:96-101.

26. Kremsner, P. G., and U. Bienzle. 1989. Soluble CD8 antigen in Plasmodium falciparum malaria. J. Infect. Dis. 160:357-358. (Letter.)

27. Kremsner, P. G., G. M. Zotter, H. Feldmeier, W. Graninger, R. M. Rocha, R. Jansen-Rosseck, and U. Bienzle. 1990. Immune response in patients during and after Plasmodium falciparum infection. J. Infect. Dis. 161:10251028.

28. Deloron, P., J. P. Lepers, and P. Coulanges. 1989. Evolution of the levels of soluble interleukin-2 receptors during Plasmodium falciparum and P. vivax malaria. J. Clin. Microbiol. 27:1887-1889.

29. Nguyen-Dinh, P., and A. E. Greenberg. 1988. Increased levels of released interleukin-2 receptors in Plasmodium falciparum malaria. J. Infect. Dis. 158:1403-1404. (Letter.)

30. Josimovic-Alasevic, O., H. Feldmeier, K. Zwingenberger, G. Harms, H. Hahn, M. Shrisuphanunt, and T. Diamantstein. 1988. Interleukin-2 receptor in patients with localized and systemic parasitic diseases. Clin. Exp. Immunol. 72:249-254.

31. Butcher, G. A., T. Garland, A. B. Ajdukiewicz, and I. A. Clark. 1990. Serum tumor necrosis factor associated with malaria in patients in the Solomon Islands. Trans. R. Soc. Trop. Med. Hyg. 84:658-661.

32. Kwiatkowski, D., J. G. Cannon, K. R. Manogue, A. Cerami, C. A. Dinarello, and B. M. Greenwood. 1989. Tumour necrosis factor production in falciparum malaria and its association with schizont rupture. Clin. Exp. Immunol. 77:361-366.

33. Peyron, F., J. P. Vuillez, G. Barbe, C. Boudin, S. Picot, and P. AmbroiseThomas. 1990. Plasma levels of tumor necrosis factor during a longitudinal survey in an endemic area of malaria. Acta Trop. 47:47-51.

34. Kwiatkowski, D. 1990. Tumour necrosis factor, fever and fatality in falciparum malaria. Immunol. Lett. 25:213-216.

35. Rhodes-Feuillette, A., M. Bellosguardo, P. Druilhe, J. J. Ballet, S. Chousterman, M. Canivet, and J. Peries. 1985. The interferon compartment of the immune response in human malaria. II. Presence of serum-interferon gamma following the acute attack. J. Interferon Res. 5:169-178.

36. Grau, G. E., G. Bieler, P. Pointaire, S. De Kossodo, F. Tacchini-Cotier, P. Vassalli, P. Piguet, and P. H. Lambert. 1990. Significance of cytokine production and adhesion molecules in malarial immunopathology. Immunol. Lett. 25:189194.

37. Aulitzky, W. E., W. K. Aulitzky, J. Frick, M. Herold, G. Gastl, H. Tilg, M. Berger, and C. Huber. 1990. Treatment of cancer patients with recombinant interferon- $\gamma$ induces release of endogenous tumor necrosis factor- $\alpha$. Immunobiology. 180:385-394.

38. Waage, A., P. Brandtzaeg, A. Halstensen, P. Kierulf, and T. Espevik. 1989. The complex pattern of cytokines in serum from patients with meningococcal septic shock: association between IL-6, IL-1, and fatal outcome. J. Exp. Med. 169:333-338.

39. Tomkinson, B. E., M. C. Brown, S. H. Ip, S. Carrabis, and J. L. Sullivan 1989. Soluble CD8 during T cell activation. J. Immunol. 142:2230-2236.

40. Herrington, D., J. Davis, E. Nardin, M. Beier, J. Cortese, H. Eddy, G. Losonsky, M. Hollingdale, M. Sztein, M. Levine, R. S. Nussenzweig, D. Clyde and R. Edelman. 1991. Successful immunization of humans with irradiated malaria sporozoites: humoral and cellular responses of the protected vaccinees. $\mathrm{Am}$ J. Trop. Med. Hyg. 45:539-547. 
41. Herrington, D. A., D. F. Clyde, J. R. Murphy, S. Baqar, M. M. Levine, V. Do Rosario, and M. R. Hollingdale. 1988. A model for Plasmodium falciparum sporozoite challenge and very early therapy of parasitemia for efficacy studies of sporozoite vaccines. Trop. Geogr. Med. 40:124-127.

42. Keller, R. J., and R. A. Jackson. 1989. Developmental regulation of serum interleukin-2 receptor concentrations: attenuation of the childhood peak in patients at risk for developing or having recently developed type I diabetes mellitus. J. Pediatr. 114:816-819.

43. Orson, F. M., C. K. Saadeh, D. E. Lewis, and D. L. Nelson. 1989. Interleukin-2 receptor expression by $\mathrm{T}$ cells in human aging. Cell. Immunol. 124:278291.

44. Teodorczyk-Injeyan, J. A., B. G. Sparkes, G. B. Mills, R. E. Falk, and W. J. Peters. 1989. Increase of serum interleukin-2 receptor level in thermally injured patients. Clin. Immunol. Immunopathol. 51:205-215.

45. Degiannis, D., J. R. Seibold, M. Czarnechi, J. Raskova, and K. Raska, Jr. 1990. Soluble and cellular markers of immune activation in patients with systemic sclerosis. Clin. Immunol. Immunopathol. 56:259-270.

46. Jodal, U., and L. A. Hanson. 1976. Sequential determination of C-reactive protein in acute childhood pyelonephritis. Acta Paediatr. Scand. 65:319-322.

47. Kushner, I., M. L. Broder, and D. Karp. 1978. Control of the acute phase response: serum $C$-reactive protein kinetics after acute myocardial infarction. $J$. Clin. Invest. 61:235-242.

48. Pepys, M. B., and M. L. Baltz. 1983. Acute phase proteins with special reference to $\mathrm{C}$-reactive protein and related proteins (pentaxins) and serum amyloid A protein. Adv. Immunol. 34:141-212.

49. Naik, P., and A. Voller. 1984. Serum C-reactive protein levels and falciparum malaria. Trans. R. Soc. Trop. Med. Hyg. 7:812-813.

50. Koj, A. 1989. The role of interleukin-6 as the hepatocyte stimulating factor in the network of inflammatory cytokines. Ann. NY Acad. Sci. 557:1-8.

51. Demetri, G. D., D. R. Spriggs, M. L. Sherman, K. A. Arthur, K. Imamura, and D. W. Kufe. 1989. A Phase I trial of recombinant human tumor necrosis factor and interferon-gamma: effects of combination cytokine administration in vivo. J. Clin. Oncol. 7:1545-1553.

52. Nussler, A., S. Pied, M. Pontet, F. Miltgen, L. Renia, M. Gentilini, and D. Mazier. 1991. Inflammatory status and pre-erythrocytic stages of malaria: role of the C-reactive protein. Exp. Parasitol. 72:1-7.

53. Pied, S., A. Nussler, M. Pontet, F. Miltgen, H. Matile, P. H. Lambert, and D. Mazier. 1989. C-reactive protein protects against pre-erythrocytic stages of malaria. Infect. Immun. 57:278-282.

54. Grifo, J. A., J. Jeremias, W. L. Ledgers, and S. S. Witkin. 1989. Interferon- $\gamma$ in the diagnosis and pathogenesis of pelvic inflammatory disease. Am. J. Obstet. Gynecol. 160:26-31.

55. Picot, S., F. Peyron, J. P. Vuillez, B. Polack, and P. Ambroise-Thomas. 1991. Chloroquine inhibits tumor necrosis factor production by human macrophages in vitro. J. Infect. Dis. 164:830. (Letter.)

56. Bhattacharya, S. K., C. R. Pillai, M. Mathur, and P. Sen. 1984. Effects of chloroquine and some other antimalarials on the immune mechanism in experimental animals. J. Pharm. Pharmacol. 36:268-269.

57. Slade, S. J., and J. Langhorne. 1989. Production of interferon-gamma during infection of mice with Plasmodium chabaudi chabaudi. Immunobiology. 179:353-365.

58. Meding, S. J., S. C. Cheng, B. Simon-Haarhaus, and J. Langhorne. 1990. Role of gamma-interferon during infection with Plasmodium chabaudi chabaudi. Infect. Immun. 58:3671-3678.

59. Rhodes-Feuillette, A., G. Jaureguiberry, J. J. Ballet, B. Andrieu, P. Druilhe, J. Le Bras, F. Galibert, and J. Peries. 1985. The interferon compartment of the immune response in human malaria. II. Interferon inducers in Plasmodium falciparum cultures. J. Interferon Res. 5:159-168.

60. Rugiero, V., J. Tavernier, W. Fiers, and C. Baglioni. 1986. Induction of the synthesis of tumor necrosis factor receptors by interferon-gamma. J. Immunol. 136:2445-2450.

61. Brown, A. E., D. A. Herrington, H. K. Webster, D. F. Clyde, M. B. Sztein, J. R. Davis, M. S. Beier, and R. Edelman. 1992. Urinary neopterin in volunteers experimentally infected with Plasmodium falciparum. Trans. R. Soc. Trop. Med. Hyg. 86:134-136.

62. Rubin, L. A., C. C. Kurman, M. E. Fritz, W. E. Biddison, B. Boutin, R. Yarchoan, and D. L. Nelson. 1985. Soluble interleukin-2 receptors are released from activated human lymphoid cells in vitro. J. Immunol. 135:3172-3177.

63. Fujimoto, J., S. Levy, and R. Levy. 1983. Spontaneous release of the Leu 2a (T8) molecule from human T cells. J. Exp. Med. 158:752-766.

64. Norment, A. M., N. Lonberg, E. Lacy, and D. R. Littman. 1989. Alternatively spliced mRNA encodes a secreted form of human CD8 $\alpha$. Characterization of the human CD8 $\alpha$ gene. J. Immunol. 142:3312-3319.

65. Bone, R. C. 1991. The pathology of sepsis. Ann. Intern. Med. 15:457-469.

66. Mossmann, T. R., H. Cherwinski, M. W. Bond, M. A. Giedlin, and R. L. Coffman. 1986. Two types of murine helper T cells. I. Definition according to profiles of lymphokine activities and secreted proteins. J. Immunol. 136:23482357.

67. Romagnani, S. 1991. Human $T_{h} 1$ and $T_{h} 2$ subsets: doubt no more. Immunol. Today. 12:256-257. 